\title{
Weakening affinity of SUS304 asperities to die surface with TiN coating for preventing delayed cracks in deep-drawn cups
}

Chin Joo Tan ( $\square$ tancj1@yahoo.com)

University of Malaya https://orcid.org/0000-0003-1079-592X

Yoong Hau Phoo

University of Malaya

\section{Research Article}

Keywords: Delayed crack, Stainless steel SUS304, Deep drawing, TiN coating, Coefficient of friction, Local wall thickening, Affinity, Surface asperities

Posted Date: August 31st, 2021

DOI: https://doi.org/10.21203/rs.3.rs-515980/v2

License: (c) (i) This work is licensed under a Creative Commons Attribution 4.0 International License.

Read Full License 


\section{Abstract}

SUS304 stainless steel has strong affinity to carbon tool steel surfaces. Therefore, the flow of material in the flange portion during the deep drawing process is retarded, leading to increase in amount of wall thicknening along the cup edge and rising risk for delayed cracks. In this paper, TiN coating is applied to the drawing die surface to weaken the affinity. Under elevated blank holding forces (BHF), the experimental results showed that the crack-free BHF range for the TiN coated and the uncoated dies are $5 \sim 10 \mathrm{kN}$ and $12 \mathrm{kN}$, respectively. The entire BHF range for successful drawn cups formed with the coated die are crack-free. The crack-free BHF magnitude is successfully lowered and the range is enlarged with the coating. Crack-free cups having large elongated height and low amount of wall thickening along the cup edge are formed. The weak affinity is evidenced by the low estimated coefficient of friction (COF) obtained from a FE simulation model based on the Coulomb's law of friction. In contrast, the estimated COF of the uncoated die is high even at the low BHF due to the strong affinity. Therefore, delayed cracks are observed under BHF range of 7 11 kN. At BHF of $12 \mathrm{kN}$, wear fragments are formed in the boundary layer as a result of the continuous polishing of the SUS304 asperities by the uncoated die asperities. The COF is sharpyly decreased due to the smooth relative movement of contacting surfaces facilitated by the particles and the formation of cracks is prevented. However, the segments tend to penetrate into the SUS304 surface under excessive BHF of $13 \mathrm{kN}$ and above. The relative motions of the segments are prohibited, resulting in the reformation of the cracks.

\section{Introduction}

SUS304 stainlss steel is a difficult-to-process material due to its strong affinity to carbon tool steel surface and high strain hardening behavior. It is a metastable austenitic stainless steel containining $18 \%$ chromium and $8 \%$ nickel. The most common type of stainless steels produced in the world is SUS304 grade. Products such as cookware products, cutlery, medical equipments and auto parts are made of SUS304. Due to the thermodynamic properties of the unstable austenite phase at room temperature, it tends to transform into a martensitic phase, i.e. strain-induced aç-martensite during deformation, leading to higher risk for delayed cracks and increase in hardness [1]. The cracking susceptibility of SUS304 increases with rising a'-martensite content [2]. Delayed cracking is a mechanism where a subcritical crack produces time-delayed cracking which there is even no external stress applied to the formed components [3]. The formation is attributed to the coexistent of the internal hydrogen content of material, residual stresses, strain-induced a'-martensitic transformation and the chemical composition of the material [4]. The presence of $a^{\prime}$-martensite is a necessary prerequisite for delayed cracking to occur in austenitic stainless steels with typical internal hydrogen concentrations ( $<5 \mathrm{ppm})$ [5]. The presence of the tiny amount of hydrogen in the steel is due to the water content in the raw materials or in the furnace gases, during pickling in mineral acids or cathodic cleaning, or during bright annealing. The variation in $a^{\prime}-$ martensitic contents under elevated blank holding forces aided by $\mathrm{SiO}_{2}$ nanolubrication resulting in the formation of crack-free or cracked SUS304 deep drawn cups had been reported [6]. Despite increasing the chance for cracks, the partial transformation of the austenite microstructure into the martensite 
microstructure results in excellent combination of strength and elongation [5]. With the combined properties, it is widely used in windshield wipers, brake springs, seat belt retractors and valve springs. It also used as raw material for contact springs, hinge springs and clamp springs in electric connectors. Delayed cracking is also affected by process parameters such as drawing ratios, forming rates and forming temperatures as the strains, residual stresses and phase transformations in the deep drawn cups are greatly influenced by these parameters [7]. The formation of a'-martensitic is also influenced by the chemical contents of the steel such as Nickel, Chromium, Carbon, and Nitrogen [8]. This may due to the close relationship between Nickel composition and the stability \& stacking fault energy of austenite. Austenitic stability promotes cross slip and, thus reduces planar slip participation in fracture to favour a macroscopically more ductile appearance. The magnitude of tensile residual stresses is increased with rising amount of strain-induced a'-martensitic [9]. Therefore, the concentration of residual stresses in the $a^{\prime}$-martensite phase is higher than the one in the austenite phase, leading to rising risk for the cracks. The tangential tensile residual stresses that attribute the cracks are considered the most vital [10]. The residual stresses can become very large i.e. up to the yielding stress value in the deep drawing process of austenitic stainless-steel blank and cause the appearance of delayed crack [11]. A simulated result indicating the highly concentrated tensile residual hoop stress zones in the valley points along the drawn cup edge after the tool separation stage had been reported [6]. Therefore, the risk for the delayed cracking in these points is higher than others. Raising the drawing ratio also increases the risk for delayed cracking due to the increase in maximum transformed martensitic fractions and residual stresses in the drawn specimens. The severity level of the delayed cracks is increased with rising drawing ratio of SUS301 cylindrical drawn cups [3]. Delayed cracking had been prevented with a deep-drawn temperature of $80^{\circ} \mathrm{C}$ due to the suppression of the martensitic transformation [7]. In addition, the transformation was also suppressed by the adiabatic heating at high forming rates. Meanwhile, warm hydro-mechanical deep drawing processes at $90^{\circ} \mathrm{C}$ had been implemented to control the formation of strain-induced aćmartensite and increase the limiting drawing ratio of SUS304 cylindrical cups from 2.0 to 3.3 [12]. Applying annealing immediately after the deep drawing is also effective in removing the residual stresses. However, despite the economic disadvantage, it is also very difficult to maintain the close tolerances and fine surface quality aspects of the products during annealing. The risk of delayed cracking is markedly reduced after annealing processes. The hydrogen content of metastable austenitic stainless steel reduced by 1 to $3 \mathrm{wt} \mathrm{ppm}$ through heat treatments at $400^{\circ} \mathrm{C}$ [6]. Cup ironing processes cause a drastic change in the residual stresses resulting in a favourable distribution for preventing the delayed cracking [11]. Decrease in sidewall thickness and change in residual stress distributions of the drawn cups are possible by enhancing the BHF during the drawing process [9]. The variation in amount of wall thickening along the cup edge and the change in cup heights under elevated BHF for the formation of cracked or crack-free cups aided by $\mathrm{SiO}_{2}$ nanolubrication had been reported [13]. Also, the increase in amount of $a$ '-martensite resulting from the higher degree of wall thickening leading to rising risk for delayed cracks had been clarified. The magnitude and the range of the crack-free BHF were too high and too narrow i.e. 29 31 kN under the nanolubrication. $\mathrm{SiO}_{2}$ nanolubrication had been successfully applied in the deep drawing processes of ultra-high strength steel and aluminium alloy cylindrical cups for increase in seizure resistance and in ironing limit [14-15]. However, continuous ultrasonic vibration of the 
$\mathrm{SiO}_{2}$ nanolubrication is needed to avoid the condensation and the agglomeration of the nanoparticles.

The deep draw-ability of ultra-high-strength steel cups had been increased with die coatings, particularly with VC-coated die [16]. A multi-point forming process as a preforming step before conducting the incremental sheet forming processing had been introduced to improve the material flow and the thickness distribution of the sheet parts, resulting in formed parts having a more uniform thickness distribution [17]. A combined process of incremental sheet metal forming and deep drawing could achieve $300 \%$ lower reduction in thinning than the ones obtained from each process separately at the same forming depth and $100 \%$ increase in drawing height had been reported [18]. Although the reduction in risk for delayed cracks is possible with the incremental sheet metal forming process, the productivity is lower than the conventional deep drawing process. Due to the excellent adhesion to substrates, resistance to elevated temperatures, hard surfaces $(2400 \mathrm{Hv})$ to reduce abrasive wear and a low coefficient of friction, TiN coating has been widely used for cutting tool and dies coating [19]. TiCN-based cermet die having fine lubricant pockets is effective in preventing the seizure in the ironing of stainlesssteel drawn cups [20]. In the industries, SUS304 is a difficult-to-machine metal due to its high affinity to carbon tool steel surface leading to high wear rate. The high hardness resulting from the formation of strain-induced martensite adding the difficulty in the deformation process.

In this study, the effect of using a finely polished uncoated die and a TiN coated die separately on the formation of delayed cracks in the deep drawing process of SUS304 cylindrical cups under the same experimental and lubrication conditions is investigated. The time taken for the 1st appearance of the cracks, the total number of cracks, drawing load profiles, cup heights, wall thickness and residual stress distributions are recorded. A 3D FE simulation of the process is performed to estimate the variation in COF under the elevated BHF. The change in affinity at the contact surface is explained with the variation of COF.

\section{Experimental And Simulation Conditions}

The chemical and mechanical properties of the SUS 304 blanks are shown in Table 1 and Table 2, respectively. It is an austenitic steel possessing of a minimum of $18 \mathrm{wt} \%$ chromium and $8 \mathrm{wt} \%$ nickel or named as 18-8 type stainless steel. It is the most common type of stainless steels used in the world due to its excellent resistant to most oxidizing acids and its ability to withstand all ordinary rusting. Both tensile strength and ductility are high making it particularly suited for both consumer and medical products.

Table 1 Chemical properties of SUS304 blanks

\begin{tabular}{|c|c|c|c|c|c|c|c|}
\hline $\mathrm{C}$ & $\mathrm{Si}$ & $\mathrm{Mn}$ & $\mathrm{P}$ & $\mathrm{S}$ & $\mathrm{Ni}$ & $\mathrm{Cr}$ & $\mathrm{Ni}$ \\
\hline 0.068 & 0.52 & 0.97 & 0.025 & 0.007 & 8.07 & 18.7 & 0.029 \\
\hline
\end{tabular}


Table 2 Mechanical properties of SUS304 blanks

\begin{tabular}{|c|c|}
\hline Tensile Strength (MPa) & 666 \\
\hline Yield strength (MPa) & 276 \\
\hline Elongation (\%) & 54 \\
\hline Hardness (Hv) & 172 \\
\hline
\end{tabular}

The experimental setup of the deep drawing test is shown in Fig. 1. A 25-ton motorised hydraulic press compresses a circular blank into a fully drawn cylindrical cup at a constant speed of $1.1 \mathrm{~mm} / \mathrm{s}$. The drawing die is positioned right below the blank holder. Six Commercial JSM coil springs (Model CB $40 \times$ 40) having a spring constant of $0.785 \mathrm{kN} / \mathrm{mm}$ are inserted into the corresponding circular holes machined inside the upper plate. The maximum deflection of the coil springs is $8 \mathrm{~mm}$. Compressing the upper plate generates the BHF acting on the blank. Two locking nuts are used to prevent the return of the coil spring and to maintin a constant BHF value during the drawing test. A 30-ton load cell is placed on top of the drawing punch through a support plate. Then, the press compresses the load cell and the press plate, resulting in the movement of the punch into the die. The distance travel of the punch is recorded by a laser distance meter pointing vertically to the press plate. Since the punch and the press plate are moving together during the compression, the punch travel distance is measured. A data logger with a sampling rate of $10 \mathrm{~Hz}$ is used to capture the signals from both the load cell and laser distance meter. Pockets are machined onto the support and the press plates, respectively to firmly hold the load cell from falling during the test.

The detailed experimental conditions are labelled in the 3D quarter model of deep drawing tool as illustrated in Fig. 2. The diameter of the punch is $\mathrm{f} 34 \mathrm{~mm}$ and the inner diameter of the die is $\mathrm{f} 37.4 \mathrm{~mm}$. Laser-cut circular SUS304 blanks measuring $72.0 \mathrm{~mm}$ in diameter with an initial measured sheet thickness of $1.18 \mathrm{~mm}$ are used in the experiment. All cups are drawn at its limiting drawing ratio of 2.12. Cutting edges around the circumferences of all blanks are all finely polished with sandpapers to remove the hard oxide layers. The commercial lubricant is applied to the blank holder-blank and the die-blank interfaces, including the die corner. However, the interface of punch bottom-blank, including the punch corner is kept dry. The punch and die corner radii are set at the same value of $5 \mathrm{~mm}$. A punch holder is used to maintain the central alignment of the punch in relative to the die during the drawing test. Each condition is repeated twice to prevent result scattering. An additional test is performed if the first two results are conflicting.

The photos of the (a) TiN coated, and (b) uncoated drawing dies are shown in Fig. 3. Both dies have the same dimensions with different surface conditions. The uncoated die is made of SKD-11 tool steel. Before each drawing test, both the uncoated die and the blank holder are polished with an orbital sander polisher machine at rotational speed of 4000 RPM using sandpapers of Grade 800 followed by Grade 1000. Finally, a solution of diamond paste with particle size ranging from 2-4 $\mu \mathrm{m}$ in a compatible diamond lubricant is used in the final stage of the polishing process. However, no polishing is applied to 
the TiN coated die surface at the beginning of each test. Only the blank holder is polished with the same method as mentioned above. TiN coating is applied to the drawing die made of tool steel by PVD coating process. The measured hardness of the coating is $763 \mathrm{Hv}$, which is approximately 4.4 times higher than the SUS304 blanks. A commercial deep drawing lubricant (ACI PRESSCUT J133) with a viscosity of 285 cSt at $40^{\circ} \mathrm{C}$ containing corrosive inhibitors and extreme pressure additives is applied to both drawing dies before each test.

The surface roughness profiles along the radial direction on the top surfaces of the TiN coated and the uncoated dies are measured using the Mitutoyo SJ-210 surface roughness tester following the ISO1997 standard. The total travel length for the stylus tip is $12.5 \mathrm{~mm}$ with a constant speed of $0.5 \mathrm{~mm} / \mathrm{s}$. The surface roughness profiles for both dies are shown in Fig. 4. The average surface roughness for the TiN coated and uncoated dies are $0.382 \mu \mathrm{m}$ and $0.581 \mu \mathrm{m}$, respectively. TiN coated die has a smoother surface than the finely polished uncoated die.

The residual stresses along the sidewall of deep-drawn cups are estimated using a ring slitting method that bases on the concept of residual stress relaxation. Deep drawn cups are sectioned with Electrical Discharge Machining (EDM) into rings. The slit rings obtained for cup heights of $30 \%, 60 \%, 80 \%$, and $100 \%$ from the bottom of the deep-drawn cup. The rings are then slit in the longitudinal direction with EDM to obtain an opening gap. Fig. 5 shows the schematic diagram for the ring slitting method. The ringopening distance, the inner diameter of the ring before slitting and the sidewall thickness of the ring are measured and recorded. The residual stresses, $s$ are then computed using the following formula:

$$
\sigma=E t\left[\frac{1}{D_{0}}-\frac{1}{D_{0}+\frac{d-s}{\pi}}\right]
$$

Where,

$E=$ modulus of elasticity $(200 \mathrm{GPa})$

$t=$ ring wall thickness

$D_{\mathrm{O}}=$ inner ring diameter before slitting

$d=$ ring-opening gap

$s=\mathrm{EDM}$ wire diameter $(0.2 \mathrm{~mm})$

The simulation of the deformation process is performed using a commercial ABAQUS/Standard software. The simulation conditions are summarized in Table 3. These values are characterized using specimen no. JIS 13B as specified in JIS Z 2201:1998 standard. The tensile tests are conducted 
following the JIS Z 2241:2011 standard at a strain rate of approximately $0.003 / s$. The initial yield stress at zero strain is $277 \mathrm{MPa}$.

Table 3 Simulation conditions [6]

\begin{tabular}{|c|c|c|}
\hline \multicolumn{2}{|l|}{ Material Properties } & Values \\
\hline \multicolumn{2}{|l|}{ Young's modulus, E (GPa) } & 190 \\
\hline \multicolumn{2}{|l|}{ Poisson ratio, $\mathrm{n}$} & 0.3 \\
\hline \multicolumn{2}{|l|}{ Yield strength (MPa) } & 297 \\
\hline \multicolumn{2}{|c|}{ Initial blank thickness $(\mathrm{mm})$} & 1.18 \\
\hline \multicolumn{2}{|l|}{ Blank holding force $(\mathrm{kN})$} & 5 to 15 \\
\hline \multicolumn{2}{|l|}{ Flow stress } & $s=1372 e^{0.43}$ \\
\hline \multirow[t]{3}{*}{ Lankford's coefficient } & & 0.954 \\
\hline & & 1.119 \\
\hline & & 0.980 \\
\hline \multirow[t]{6}{*}{ Anisotropic Yield Criterion } & R11 & 1 \\
\hline & R22 & 1.0069 \\
\hline & R33 & 0.9951 \\
\hline & R12 & 0.9575 \\
\hline & R13 & 1 \\
\hline & R23 & 1 \\
\hline
\end{tabular}

The quarter FE model of the deep drawing process is shown in Fig. 6. All tools are modelled as discrete rigid and meshed with four-node tetrahedral elements. The blank has an initial wall thickness of $1.18 \mathrm{~mm}$ and is divided into deformable 3D shell elements (four-node doubly curved thin shell, reduced integration, hourglass control, finite membrane strains) with five integration points across its thickness following Simpson's rules. Since the solid elements have locking problem during bending, shell elements are used to model the thin sheet in this study as it consumes less disk space for the results and the postprocessing of the shells is faster. The average mesh size of the blank is $1.2 \mathrm{~mm}$. The blank is defined as an elastic-plastic material model following the isotropic hardening law. A ring-shaped insert measuring a wall thickness of 1.16 or $0.02 \mathrm{~mm}$ less than the blank thickness is added between the holder and the die outside the circumference of the blank to prevent the direct contact between the two rigid tools after the flange being pulled out from the holding region. Hence, the termination of the simulation process is prevented. A lifter is placed right below the blank and in contact with the bottom surface. Both the punch and lifter are displaced by $41.0 \mathrm{~mm}$ and $41.1 \mathrm{~mm}$, respectively during the drawing process. With the additional $0.1 \mathrm{~mm}$ of displacement, the reaction force of the lifter would not increase the peak drawing load of the punch. The total drawing load profile is obtained by subtracting the punch loads from the lifter loads in opposite direction along the displacement and multiplied by four taking into the consideration of the full 3D model. Lifter is used in the simulation only for establishing a more stable contact between the tools and the blank surfaces. A homogenous coulomb friction is assumed for all contact surfaces between the tools and the blank. A penalty friction of 0.5 is assumed for dry contact 
interfaces of punch/blank and lifter/blank. The penalty friction for the lubricated interfaces i.e. blankholder/blank and die/blank are estimated by matching the simulated load profiles with the experimental profiles for both the coated and uncoated dies. The COF is increased at 0.01 increment to match the simulated peak load with the experimental one until the necking occur as shown in Fig. 6(c). The COF limit of the successful drawn cup are determined. The advanced methods for predicting forming defects such as local thinning in the deep drawing process had been reported [21]. A new dimensionless method for estimating the deep drawing force had been reported [22]. The only dimensionless parameter that can significantly change the drawing force is the coefficient of friction.

\section{Experimental Results}

The drawn cups formed with the finely polished uncoated die at elevated BHF are summarized in Fig. 7. The lowest BHF limit for a successful drawn cup is determined at $7 \mathrm{kN}$ as wrinkle is observed in the cup formed at $\mathrm{BHF}=6 \mathrm{kN}$. Tearing is observed around the cup bottom due to the stretching by the punch corner during the drawing process under an excessive BHF of $16 \mathrm{kN}$. Therefore, the BHF range for the successful drawn cups is from $7 \sim 15 \mathrm{kN}$. Within this range, delayed cracks are observed in all cups except the one for $\mathrm{BHF}=12 \mathrm{kN}$. Most of the delayed cracks are observed around the valley points of the cups due to the large amount of wall thickening resulting from the short height. All drawn cups have four ears consisting of 4 peak and 4 valley points.

The number of cracks and the time taken for its first appearance in the cups formed with the uncoated die are summarized in Table 4. The time is recorded immediately after completing the test until the formations of all cracks are complete. It clearly shows that the duration for the first crack increases with increase in BHF. The formation of the cracks is gradually suppressed with increase in BHF. However, the suppression becomes weak when excessive BHFs are applied i.e. from $14 \mathrm{kN}$ and above. A crack-free cup is obtained under BHF of $12 \mathrm{kN}$. The highest number of cracks is obtained with BHF $=13 \mathrm{kN}$, followed by $8 \mathrm{kN}$ and others. The longest duration for the first crack is obtained at BHF of $13 \mathrm{kN}$. The duration sharply decreases for BHF greater than $13 \mathrm{kN}$.

Table 4 Number of cracks and time taken for its first appearance for uncoated die 


\begin{tabular}{|c|c|c|}
\hline $\begin{array}{c}\text { BHF } \\
(\mathrm{kN})\end{array}$ & No. of Cracks & $\begin{array}{c}\text { Duration for 1st Crack } \\
(\mathrm{hrs})\end{array}$ \\
\hline 6 & 1 & 5 \\
\hline 7 & 1 & 8 \\
\hline 8 & 2 & 9.5 \\
\hline 9 & 1 & 9 \\
\hline 10 & 1 & 11 \\
\hline 11 & 1 & 14 \\
\hline 12 & \multicolumn{2}{|c|}{ Crack-free } \\
\hline 13 & 3 & 4 \\
\hline 14 & 1 & 4 \\
\hline 15 & 1 & \multicolumn{2}{|c|}{ Tearing at bottom } \\
\hline 16 & \multicolumn{2}{|c|}{} \\
\hline
\end{tabular}

The data in Table 4 are summarized and presented in Fig. 8. The duration for the 1 st crack increases with the increase in BHF. The crack is successfully eliminated at BHF $=12 \mathrm{kN}$. The duration and the number of cracks hit the peak values of 14 hours and 3 cracks at BHF $=13 \mathrm{Kn}$. Both values sharply reduce to 4 hours and only 1 crack for BHF from $14 \sim 15 \mathrm{kN}$.

The drawn cups formed with the TiN coated die at elevated BHF is shown in Fig. 9. Wrinkle and tearing around cup bottoms are observed at BHF $=4 \mathrm{kN}$ and $11 \mathrm{kN}$, respectively. Therefore, the BHF range for successful drawn cups is $5 \sim 10 \mathrm{kN}$. In comparison to the uncoated die, the successful BHF range is reduced from $7 \sim 15 \mathrm{kN}$ to $5 \sim 10 \mathrm{kN}$. The width of the successful BHF range is only $2 / 3$ of the one obtained with the uncoated die. However, the lower BHF limit for the wrinkle-free cups is reduced from 7 $\mathrm{kN}$ to $5 \mathrm{kN}$. Delayed cracks are not observed in the entire BHF range for successful drawn cups formed with the coated die. Lower and wider BHF ranges are preferred in the industries as it is difficult to maintain a precise, constant and high BHF value with coil springs or die cushion during the process.

The comparison of forming load profiles between cups formed with (a) TiN coated die and (b) Uncoated die is shown in Fig. 10. Since the two dies have the same dimensions, typical bell-shape drawing load profiles are obtained for both dies. The increase in drawing load is very minimum for increase in BHF values in both cases. Peak drawing loads range from $105 \sim 115 \mathrm{kN}$ are obtained around $60 \%$ of the total punch travel distance for both dies.

The comparison of the experimental and the simulated peak drawing loads between the TiN coated and the uncoated dies under elevated BHF is shown in Fig. 11. Overall, the experimental peak loads for the coated die are lower than that of the uncoated die within the BHF range for successful drawn cups. For the coated die, the peak loads increased linearly under the elevated BHF. This trend agreed well with the Coulomb friction law i.e. under the same boundary condition, the drawing load increases with increasing BHF. Therefore, the simulated peak loads also showed the similar trend with the experimental ones under a constant coefficient of friction (COF) of 0.27 despite having a bias error of $6.9 \sim 7.8 \mathrm{kN}$ or $6.4 \sim 7.3 \%$ 
between the experimental and the simulated values. Necking is observed around the side wall of the cup in the simulation when the COF is increased to greater than 0.27 for BHF of $10 \mathrm{kN}$. Therefore, the COF is kept at 0.27 for BHF from $5 \mathrm{kN}$ to $9 \mathrm{kN}$ while maintaining the same bias error level. The COF of 0.27 for SUS304/TiN interface is slightly lower than the measured COF of 0.3 from the micro-scale abrasion test [23].

In contrast, the change in experimental peak loads for the uncoated die is very minimal i.e. maintained at approximately $113 \mathrm{kN}$ level for increase in BHF. This trend didn't agree well with the Coulomb friction law for the deformation under the same boundary condition. The estimated COF under the elevated BHF for the uncoated die is illustrated in Fig. 10 (b). For BHF of $10 \mathrm{kN}$ and above, the COF in the simulation is set to its upper limit for obtaining successful drawn cups and the peak loads are recorded. The COF for BHF of less than $10 \mathrm{kN}$, the COF is increased to maintain the same bias error of $7.7 \sim 8.9 \mathrm{kN}$ or $6.8 \sim 7.8 \%$. The bias error for BHF of $10 \mathrm{kN}$ and above is $7.5 \sim 9.9 \mathrm{kN}$ or $6.6 \sim 8.8 \%$. Overall, COF decreased with rising BHF under the same lubrication condition. It has a similar trend with the cups formed under elevated $\mathrm{BHF}$ using $\mathrm{SiO}_{2}$ nanolubrication [13]. This may be attributed to the strong affinity of SUS304 asperities to the finely polished uncoated die surface. For uncoated die, galling or cold welding tends to form between the surface asperities along the contact surface. The galling effect or the continuous forming and breaking of the welds has produced some wear fragments that facilitate the sliding motion of the tool over the blank, resulting in lower COF value under elevated BHF. Therefore, the stretching force in radial direction is reduced, leading to decrease in cup elongated height and increase in amount of wall thickening along the cup edge. The chance for delayed crack increases under such circumstances. On the other hand, the absence of wear fragments at the SUS304-TiN interface due to the high surface integrity of the coating, particularly at low BHF range increased the stretching force along the radial direction of the cup during the drawing process, resulting in larger elongated cup height and smaller amount of wall thickening. The chance for delayed crack is decreased with the coated die.

The comparison of the average heights and the average changes in wall thickness between the drawn cups formed with the TiN coated and uncoated dies at elevated BHF is shown in Fig. 12. Overall, the average cup height formed with the coated die is larger than the uncoated die. The peak and valley heights are slightly increased with increase in BHF for both dies. The heights hit peak values at BHF of 8 $\mathrm{kN}$ and $12 \mathrm{kN}$ for the coated and uncoated dies, respectively. Since the only crack-free cup is obtained at the peak height for uncoated die with BHF of $8 \mathrm{kN}$, increase in cup height, particularly in the valleys is favourable for eliminating the delayed crack. By applying TiN coating to the die surface, larger cup heights are obtained with lower BHF values. Overall, the wall thickness in the valleys for the cups formed with the coated die is smaller than the ones formed with the uncoated die. However, the wall thickness in the peaks for the cups formed with the coated die is at the same level with the uncoated die. Due to constant volume, the materials contributing to the elongated height is originated from the side wall below the cup edge. The average changes in wall thickness in the peaks and the valleys are slightly reduced with increase in BHF for both dies. The average thickness hit minimum percentages at BHF of $8 \mathrm{kN}$ and $12 \mathrm{kN}$ for the coated and uncoated dies, respectively. 
The relationship between the average changes in wall thickness and the average heights of the peaks \& valleys of the crack-free cups formed with the TiN coated die is illustrated in Fig. 13. Overall, the average wall thickness is increased, and the height is reduced with increase in BHF. The largest height and the smallest wall thickness for both points are obtained at BHF of $8 \mathrm{kN}$. Under excessive BHF i.e. greater than $8 \mathrm{kN}$, the tribological performance of the lubricant becomes poor, leading to the reverse trend of both values. However, delayed cracks are not observed in the drawn cups up to the upper BHF limit of $10 \mathrm{kN}$.

The relationship between the average changes in wall thickness and the average heights of the peaks \& valleys of the cups formed with the uncoated die is illustrated in Fig. 14. A similar trend of increase in height and decrease in amount of wall thickening under elevated BHF is obtained with the uncoated die. However, the largest height and the smallest wall thickness for both points are obtained at BHF $=12 \mathrm{kN}$ or $50 \%$ higher than one with the coated die. The minimum BHF for obtaining a crack-free cup with the coated die is $140 \%$ (i.e. reduced from $12 \mathrm{kN}$ to $5 \mathrm{kN}$ ) less than one with the uncoated die.

The longitudinal distributions of residual hoop stresses passing through the valley points along the outer surfaces of the crack-free cups obtained from the ring-slitting test are shown in Fig. 15. Overall, the amount of tensile residual stresses of the cup formed with the uncoated die is larger than the ones formed with the coated die in the lower half of the cups due to its high BHF value. For coated die, the increase in BHF reduces both the amount of tensile stresses and the slope of the stress for greater than $80 \%$ of its total height. Low tensile residual stress level with less gradient, particularly in the upper portion along the outer surface of cups is favourable for eliminating the delayed cracks. The favourable residual stress distribution is obtained with the TiN coated die at BHF values much lower than that with the coated die.

\section{Conclusions}

The effect of TiN coated die on eliminating the delayed cracks in the deep drawing process of stainless steel SUS304 cylindrical cups under elevated BHF is investigated in the experiment at room temperature. FE simulation is performed to estimated the COF of the process under different BHF. The results are summarized as follow:

(a) The crack-free BHF ranges for the cups formed with the coated and uncoated dies are $5 \sim 10 \mathrm{kN}$ and $12 \mathrm{kN}$, respectively. The width of the range is enlarged by 6 times by means of the TiN coating, resulting in a robust process.

(b) The minimum BHF for obtaining a crack-free cup with the coated die is $140 \%$ (i.e. reduce from $12 \mathrm{kN}$ to $5 \mathrm{kN}$ ) less than the one with the finely polished uncoated die.

(c) The elimination of the cracks is mainly due to the decrease in amount of wall thickening and increase in elongated cup height, particularly in the valley points along the earring profiles. Less amount of strain-induced martensite is formed with the low degree of wall thickening, resulting in low risk for the cracks. 
(d) The lower COF of the coated die is a result of the weaker affinity of SUS304 asperities to the TiN coating. The flow of material is enhanced in the flange portion resulting in large elongated cup height, low degree of wall thickening and low chance for cracks.

(e) The favourable residual stress distribution for eliminating the delayed cracks is obtained with the TiN coated die at BHF values much lower than that with the coated die.

\section{Declarations}

The authors declare that there is no conflict of interest

\section{References}

[1] Kim YH, Kim KY, Lee YD. Nitrogen-alloyed, metastable austenitic stainless steel for automotive structural applications. Mater Manuf Process 2004; 1(1): 51-59. https://doi.org/10.1081/amp1200274981

[2] Hannu $\mathrm{H}$, Tero $\mathrm{H}$. On the effects of a'martensite in hydrogen embrittlement of a cathodically charged AISI type 304 austenitic stainless steel. Corrosion 1980; 36(1): 47-51. https://doi.org/10.5006/00109312-36.1.47

[3] Papula S, Saukkonen T, Talonen J, et al. Delayed Cracking of Metastable Austenitic Stainless Steels after Deep Drawing. ISIJ Int 2015; 55(10): 2182-2188. https://doi.org/10.2355/isijinternational.isijint2015-078

[4] Zinbi A, Bouchou A. Delayed cracking in 301 austenitic steel after bending process: Martensitic transformation and hydrogen embrittlement analysis. Eng Fail Anal 2010; 17(5): 10281037. https://doi.org/10.1016/j.engfailanal.2009.11.007

[5] Papula S, Talonen J, Hänninen H. Effect of residual stress and strain-induced a'-martensite on delayed cracking of metastable austenitic stainless steels. Metall Mater Trans A Phys Metall Mater Sci 2014; 45(3): 1238-1246. https://doi.org/10.1007/s11661-013-2090-3

[6] Tan CJ, Aslian A. FE simulation study of deep drawing process of SUS304 cups having no delayed cracks under enhanced blank holding force. P I Mech Eng B J Eng 2019; 234(1-2): 84-

94. https://doi.org/10.1177/0954405419855230

[7] Guo X, Black W. Delayed cracking in high strength steels. In: Wolfgang B (ed) 23. Aachener Stahlkolloquium: Stahl-ein exzellenter Werkstoff, Aachen, 2008. p. 59-69.

[8] Berrahmoune MR, Berveiller S, Inal K, et al. Delayed cracking in 301LN austenitic steel after deep drawing: Martensitic transformation and residual stress analysis. Mater Sci Eng A 2006; 438-440: 262266. https://doi.org/10.1016/j.msea.2006.02.189 
[9] El Sherbiny M, Zein H, Abd-Rabou M, et al. Thinning and residual stresses of sheet metal in the deep drawing process. Mater Design 2014; 55: 869-879. https://doi.org/10.1016/j.matdes.2013.10.055

[10] Ortega S, Papula S, Saukkonen T, et al. Characterization of delayed cracking in deep-drawn Swift cups of metastable austenitic stainless steels. Fatigue Fract Eng Mater Struct 2015; 38(1): 2939. https://doi.org/10.1111/ffe.12206

[11] Danckert J. Reduction of the residual stresses in a deep-drawn cup by modifying the draw die profile. CIRP Ann Manuf Technol 1995; 44(1): 259-262. https://doi.org/10.1016/S0007-8506(07)62321-X

[12] Xu Y, Kang D. Investigation of SUS304 stainless steel with warm hydro-mechanical deep drawing. $J$ Mater Sci Technol 2009; 20(01): 92-93.

[13] Tan CJ, Ibrahim MS, Muhamad MR. Preventing delayed cracks in SUS304 deep drawn cups using extreme blank holding forces aided by nanolubrication. Int J Adv Manuf Technol 2019; 100: 13411354. https://doi.org/10.1007/s00170-018-2772-5

[14] Tan CJ, Aslian A, Abe Y, et al. Improved seizure resistance of ultra-high-strength steel ironed cups with a lubricant containing SiO2 nanoparticles. Int J Adv Manuf Technol 2016; 87: 17051711. https://dx.doi.org/10.1007/s00170-016-8588-2

[15] Tan CJ, Abe Y, Daodon W, et al. Increase in ironing limit of aluminium alloy cups with lubricants containing nanoparticles. J Mater Process Techno/ 2016; 229: 804-

813. http://dx.doi.org/10.1016/j.jmatprotec.2015.10.032

[16] Abe Y, Ohmi T, Mori K, et al. Improvement of formability in deep drawing of ultra-high strength steel sheets by coating of die. J Mater Process Techno/ 2014; 214(9): 18381843. https://doi.org/10.1016/j.jmatprotec.2014.03.023

[17] Zhang H, Lu B, Chen J, et al. Thickness control in a new flexible hybrid incremental sheet forming process. P I Mech Eng B J Eng 2017; 231(5):779-791. https://doi.org/10.1177/0954405417694061

[18] Tandon P, Sharma ON. Experimental investigation into a new hybrid-forming process: incremental stretch drawing. P I Mech Eng B J Eng 2018; 232(3): 475486. https://doi.org/10.1177/0954405416645983

[19] Zhang S, Zhu W. TiN coating of tool steels: a review. J Mater Process Technol 1993; 39(1-2): 165177. https://doi.org/10.1016/0924-136(93)90016-Y 
[20] Abe Y, Mori K, Hatashita F, et al. Improvement of seizure resistance in ironing of stainless steel cup with cermet die having fine lubricant pockets. J Mater Process Technol 2016; 234: 195-

207. https://doi.org/10.1016/j.jmatprotec.2016.03.017

[21] Takalkar Atul S, Lenin Babu MC. A review on effect of thinning, wrinkling and spring-back on deep drawing process. P I Mech Eng B J Eng 2019; 233(4): 1011-

1036. https://doi.org/10.1177/0954405417752509

[22] Hajiahmadi S, Elyasi M, Shakeri M. Evaluation of drawing force by a new dimensionless method in deep drawing process. P I Mech Eng B J Eng 2020; 234(13), 1604-

1614. https://doi.org/10.1177/0954405420929770

[23] Numchoak S, Warit S, Krittatee S, et al. Wear characteristics of die surface in deep drawing of stainless steel 304 by using finite element simulation. MATEC Web Conf. 2018; 192;

01040. https://doi.org/10.1051/matecconf/201819201040

\section{Figures}

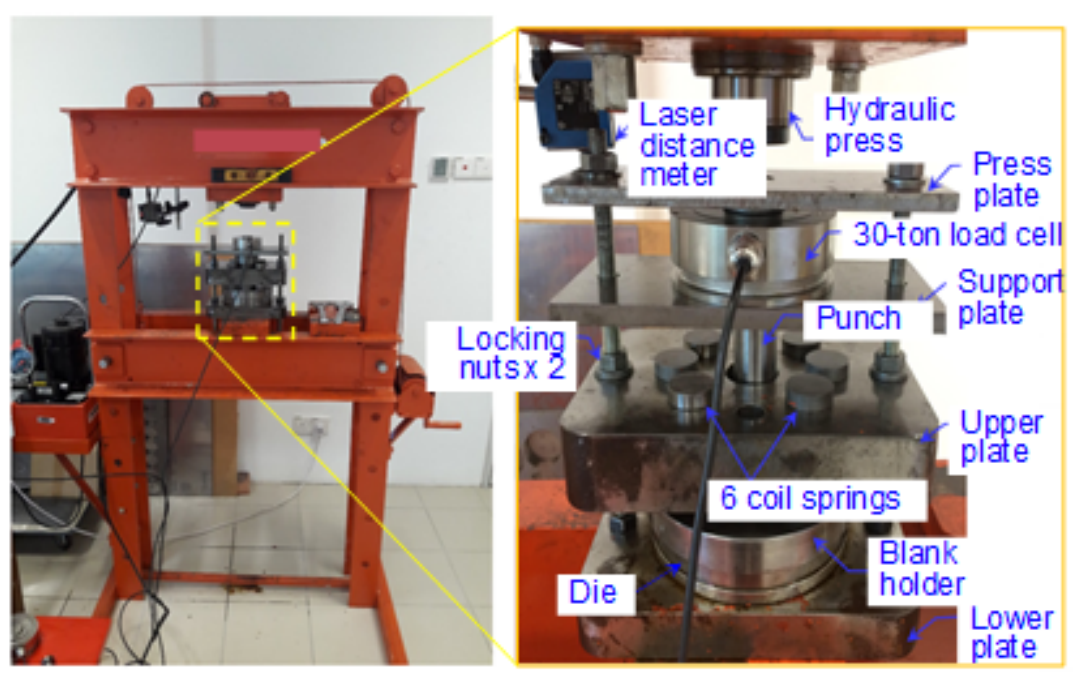

\section{Figure 1}

Experimental setup 


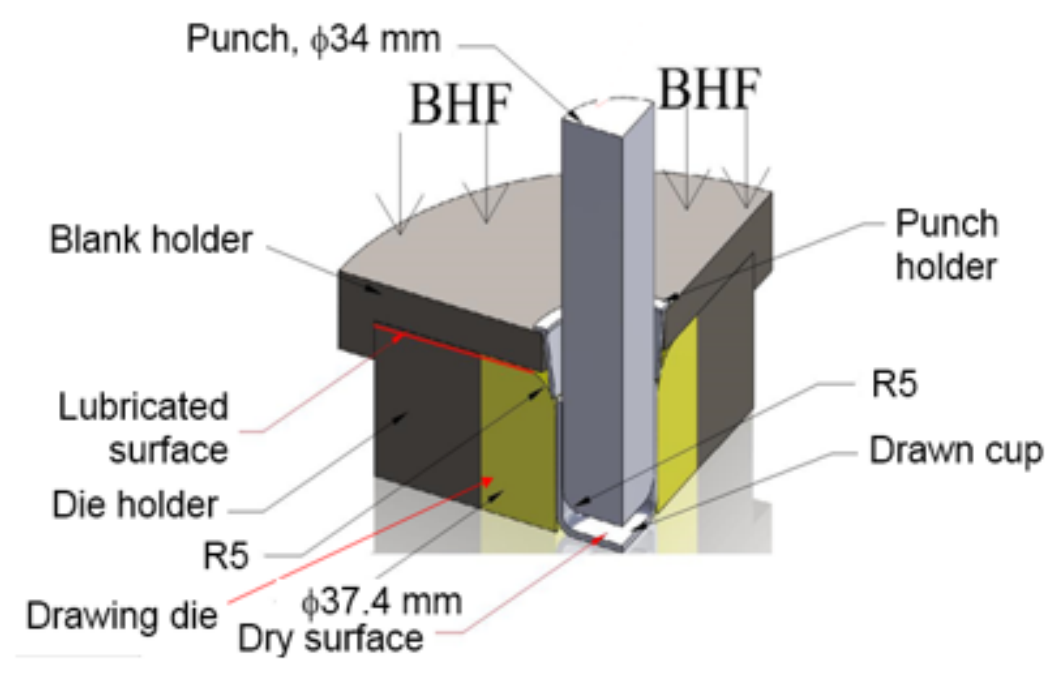

Figure 2

3D quarter model of deep drawing tool

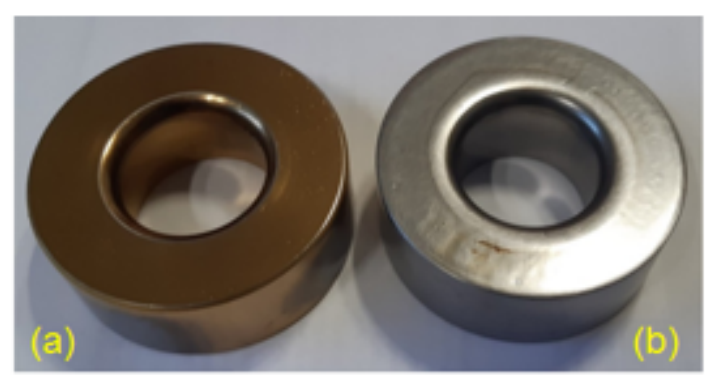

Figure 3

(a) TiN coated and (b) finely polished uncoated drawing dies 


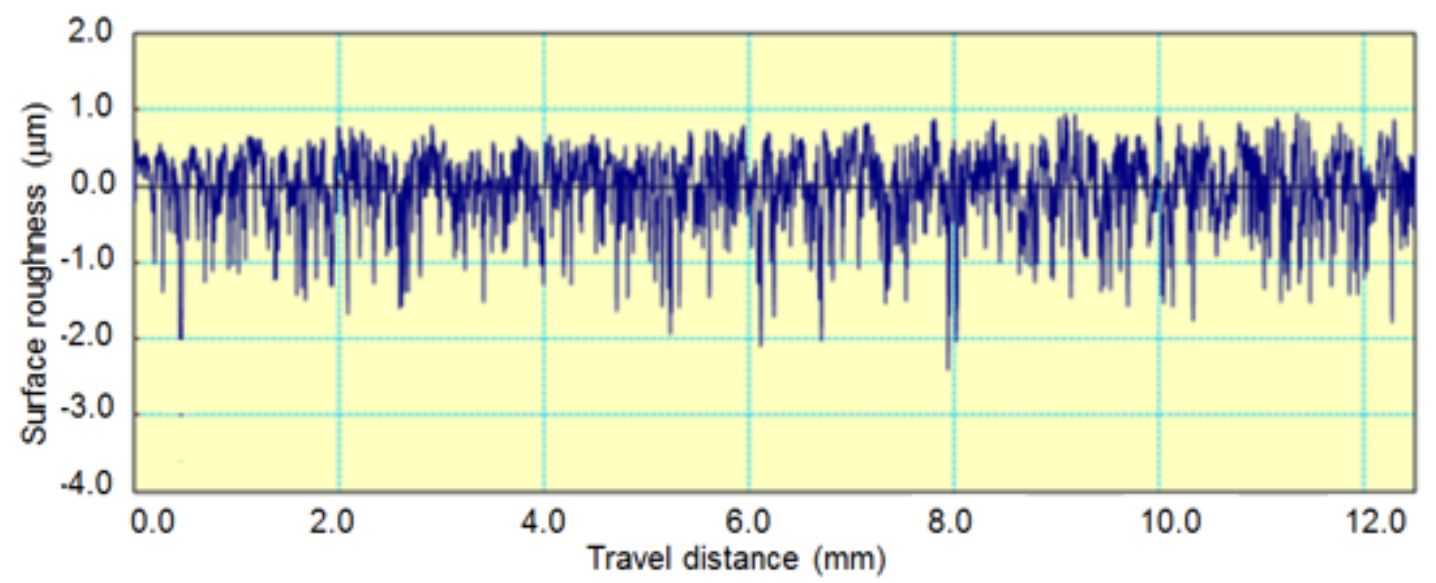

(a) TiN coated die

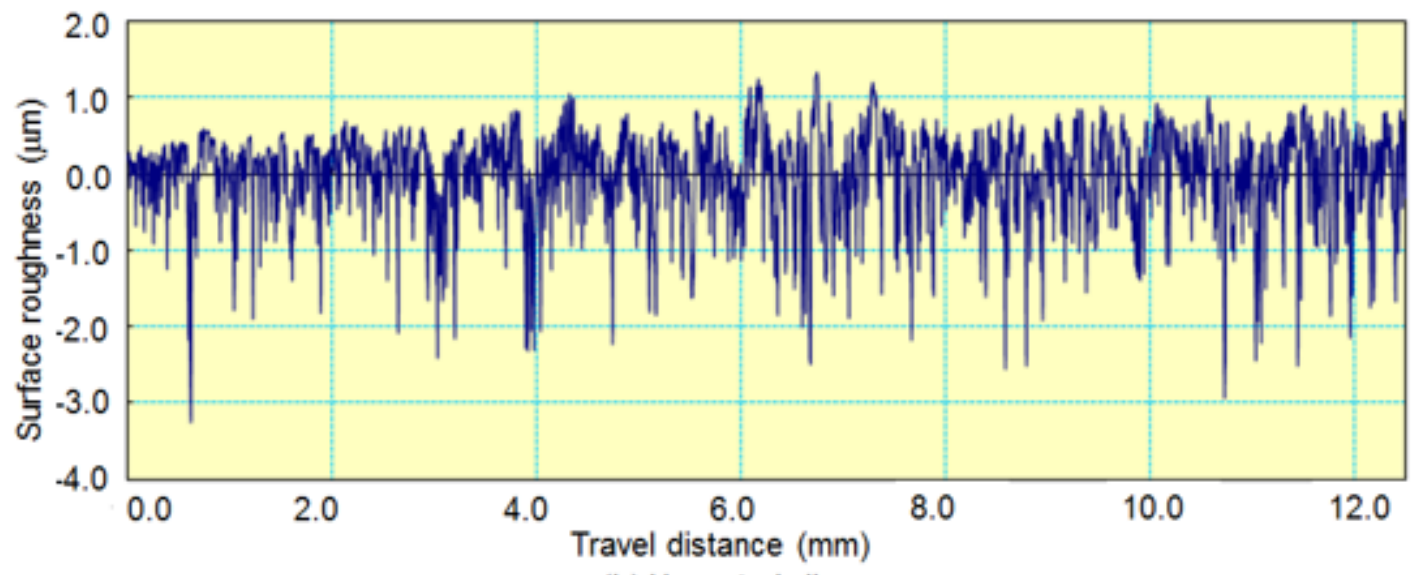

(b) Uncoated die

Figure 4

Surface roughness profiles for (a) TiN coated die \& (b) uncoated die
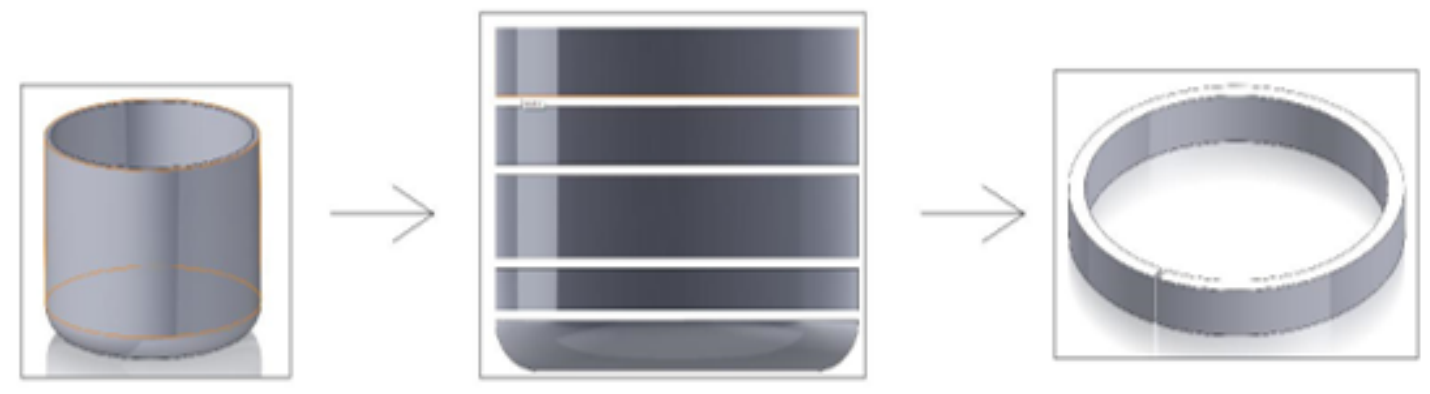

Figure 5

Ring slitting method 


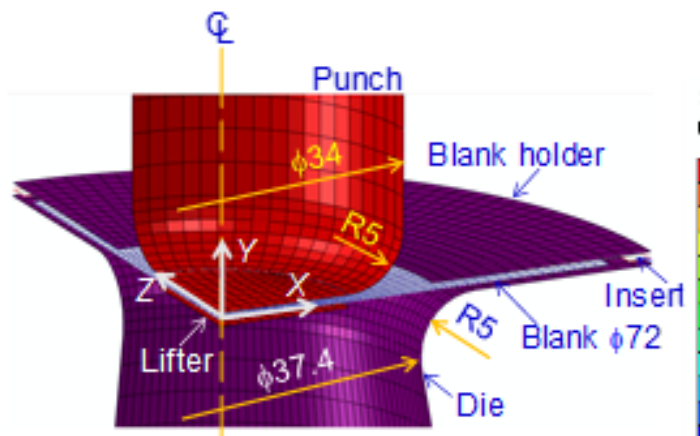

(a) Quarter FE model

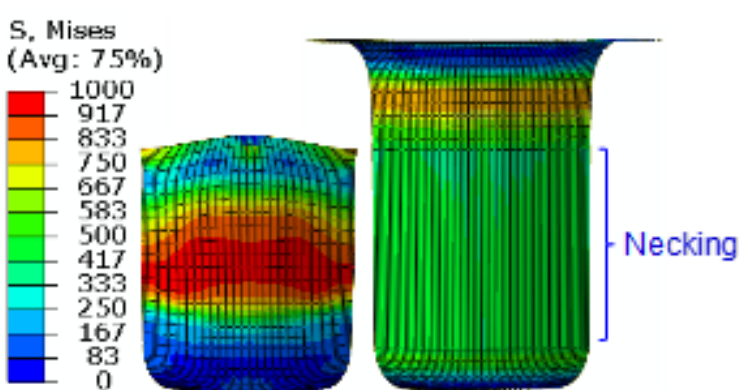

(b) Successful drawn cup for BHF $13 \mathrm{kN}$ \& COF 0.24 (c) Failed cup for BHF $13 \mathrm{kN}$ \& COF 0.25

Figure 6

Quarter FE model of deep drawing process and drawn cups obtained from simulation

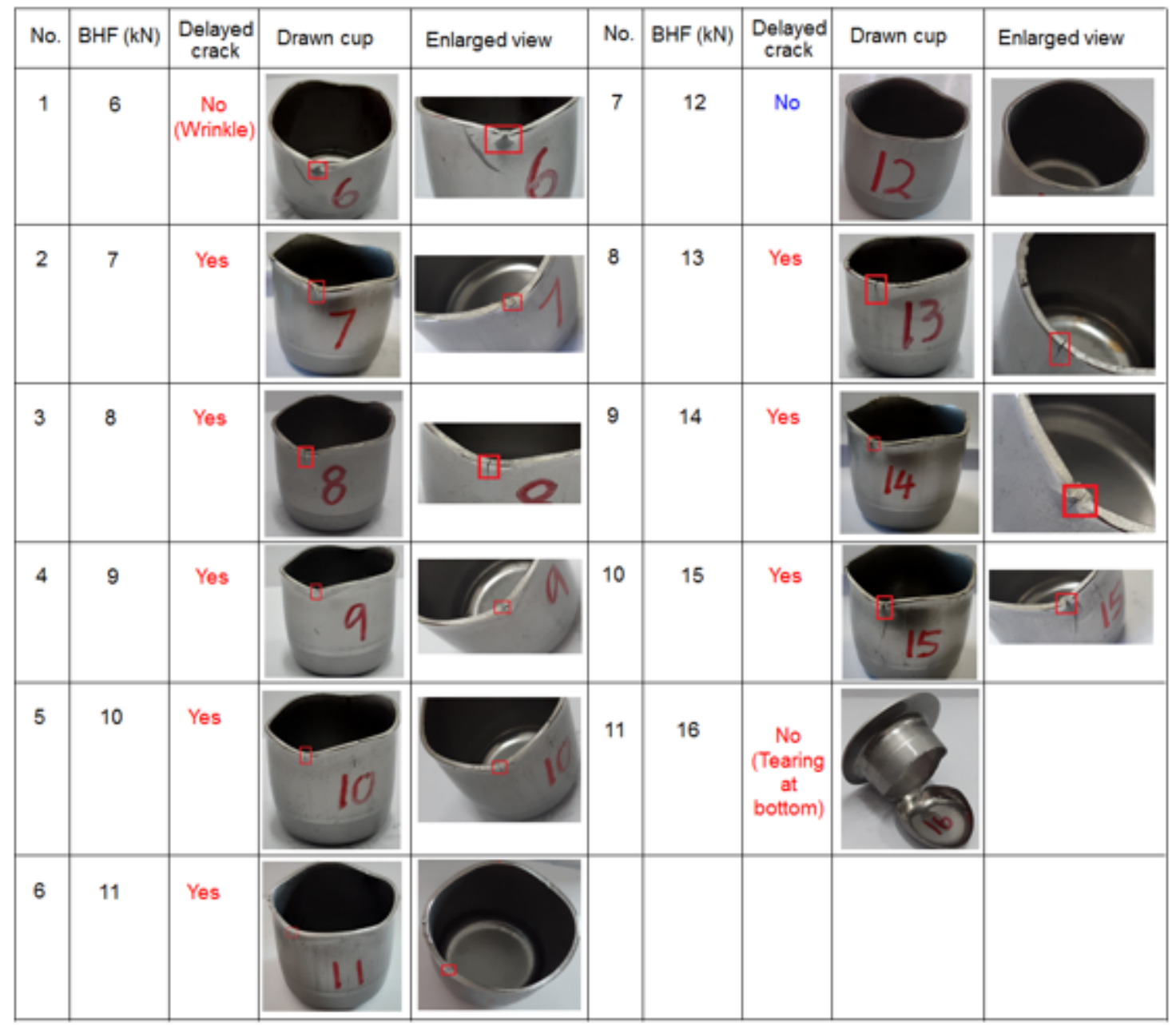

\section{Figure 7}

Drawn cups formed with finely polished uncoated die at elevated BHF 


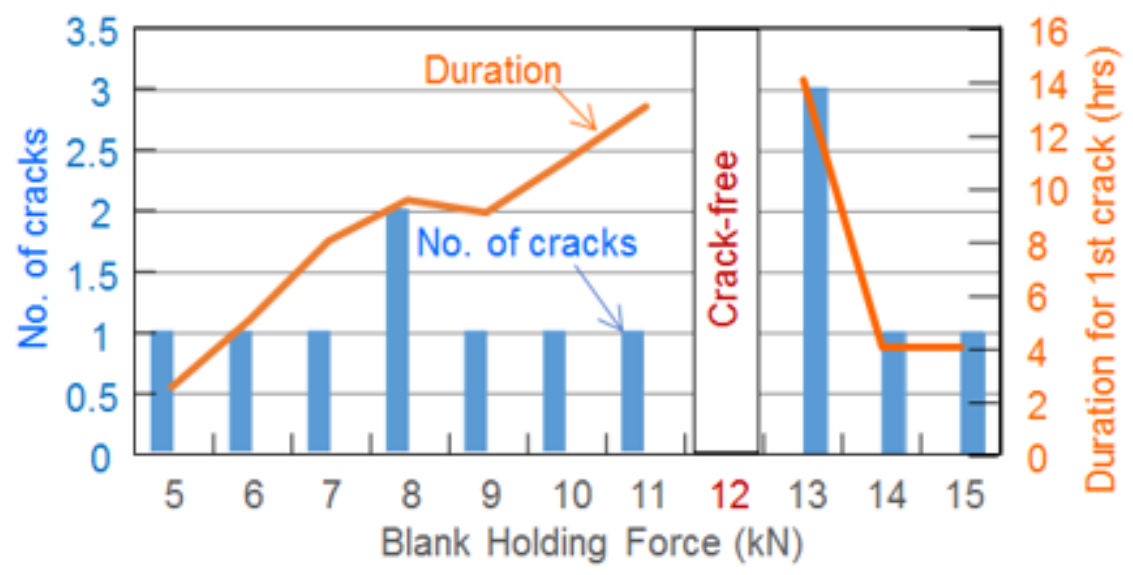

\section{Figure 8}

Number of delayed cracks and time taken for $1 \mathrm{st}$ appearance of crack in drawn cups formed with coated die

\begin{tabular}{|c|c|c|c|c|c|c|c|c|c|}
\hline No. & $\mathrm{BHF}(\mathrm{kN})$ & \begin{tabular}{|c|}
$\begin{array}{c}\text { Delayed } \\
\text { crack }\end{array}$ \\
\end{tabular} & Drawn cup & Enlarged view & No. & $\mathrm{BHF}(\mathrm{kN})$ & \begin{tabular}{|c|} 
Delayed \\
crack
\end{tabular} & Drawn cup & Enlarged view \\
\hline 1 & 4 & $\begin{array}{c}\text { No } \\
\text { (Wrinkle) }\end{array}$ & & & 7 & 8 & No & & \\
\hline 2 & 5 & No & & & 8 & 9 & No & & \\
\hline 3 & 6 & No & & & 9 & 10 & No & & \\
\hline 4 & 7 & No & & & 10 & 11 & Tearing & & \\
\hline
\end{tabular}

Figure 9

Drawn cups formed with TiN coated die at elevated BHF 


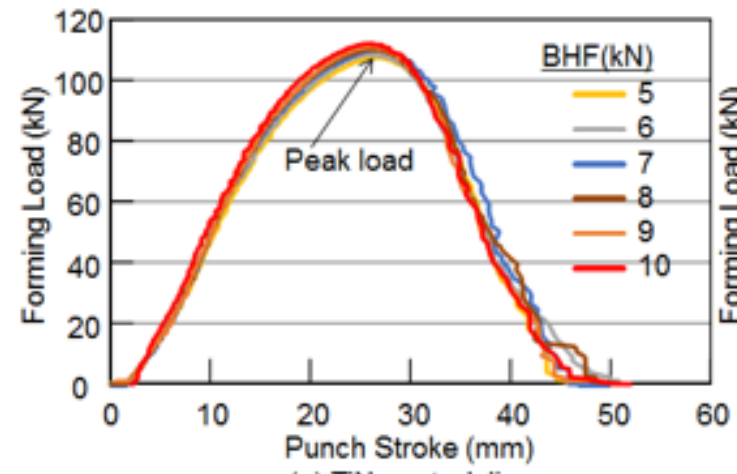

(a) TiN coated die

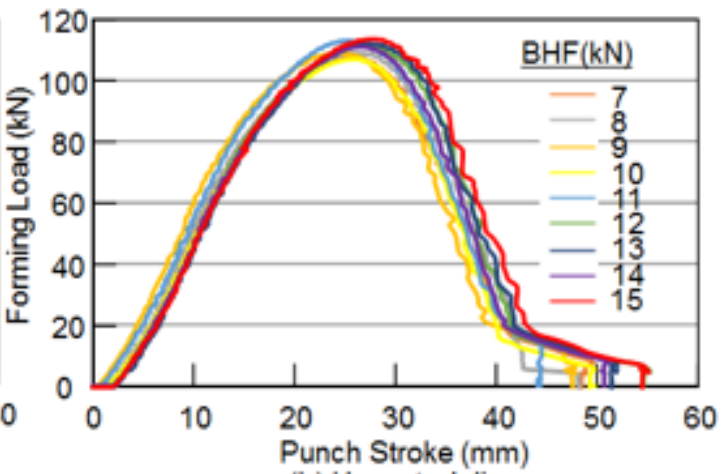

(b) Uncoated die

Figure 10

Comparison of forming load profiles between cups formed with (a) TiN coated die and (b) Uncoated die

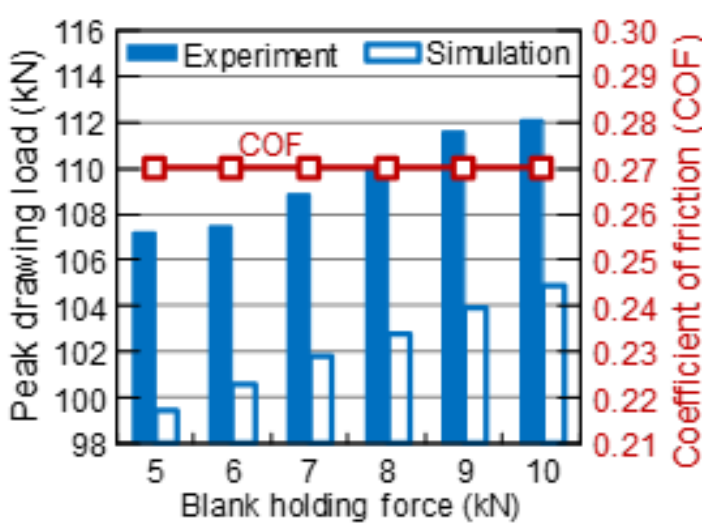

(a) Coated die

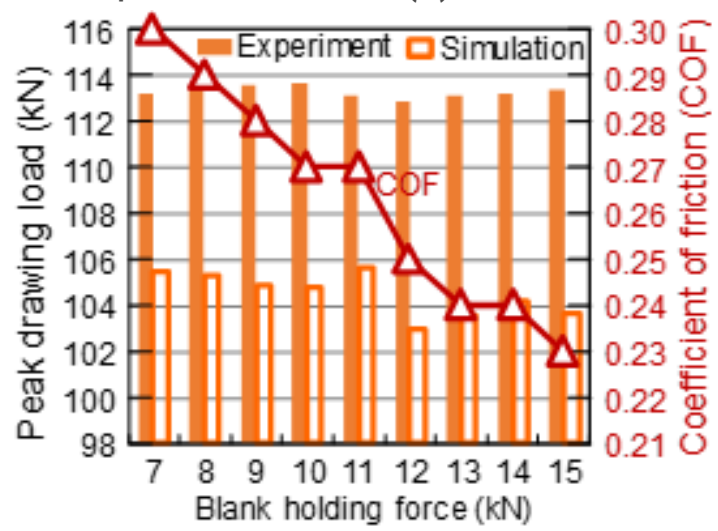

(b) Uncoated die

\section{Figure 11}

Comparison of experimental and simulated peak loads between TiN coated and uncoated dies under elevated BHF

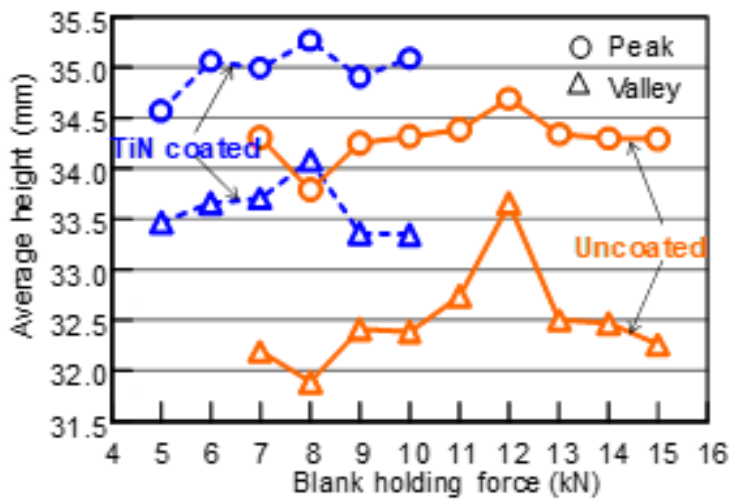

(a) Average height of peak and valley points

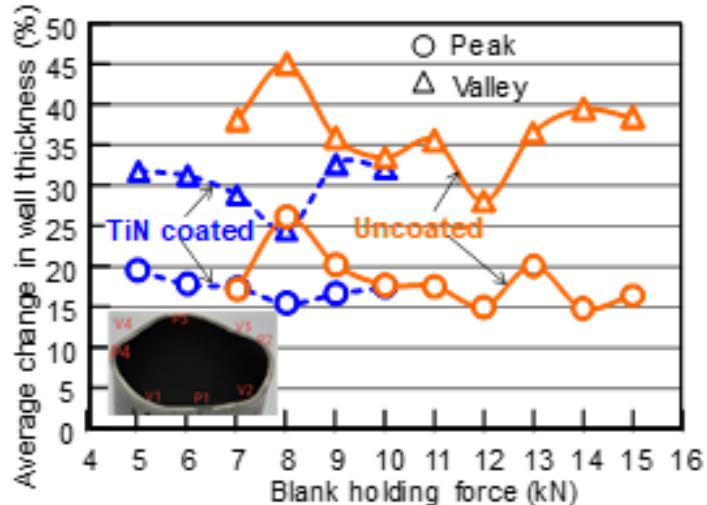

(b) Average change in wall thickness in peak and valley points 
Comparison of average heights and average changes in wall thickness between drawn cups formed with TiN coated and uncoated dies at elevated BHF

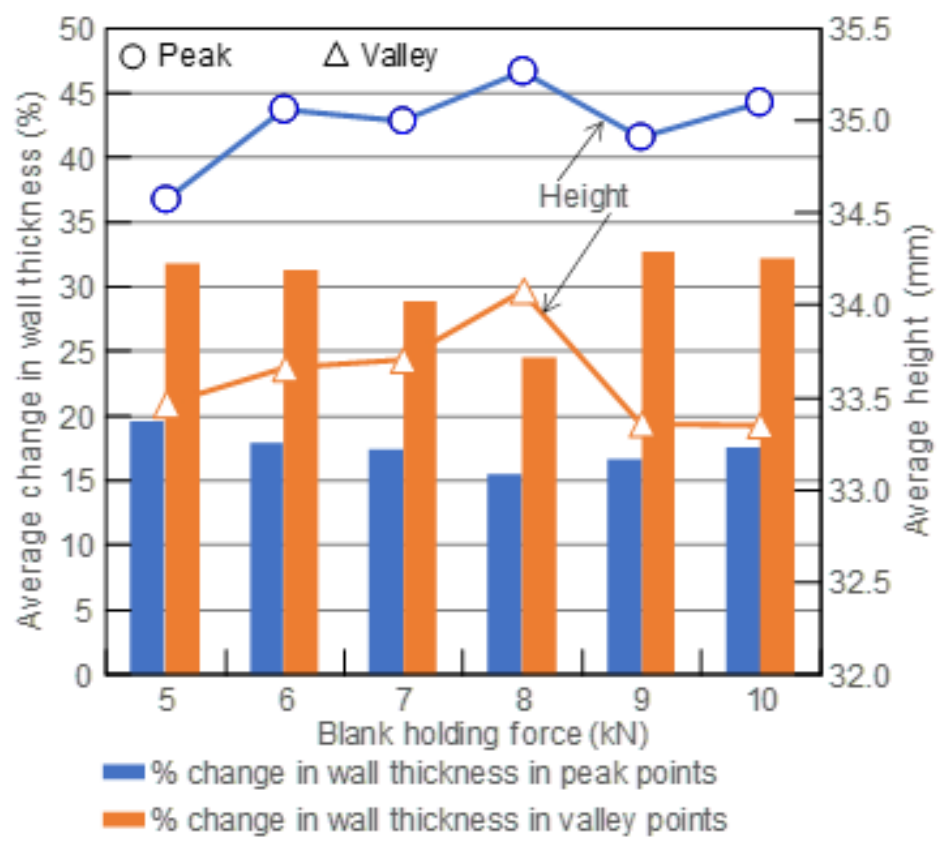

\section{Figure 13}

Average changes in wall thickness and average heights of crack-free cups formed with TiN coated die

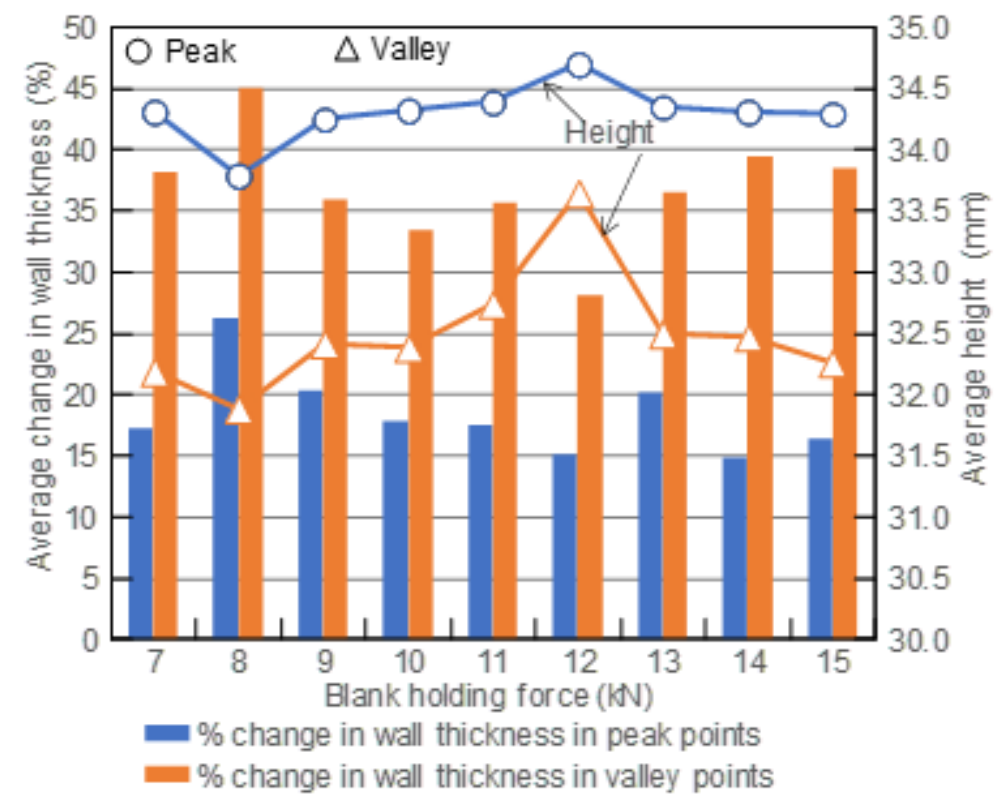

\section{Figure 14}

Average changes in wall thickness and average heights of crack-free cups formed with uncoated die 


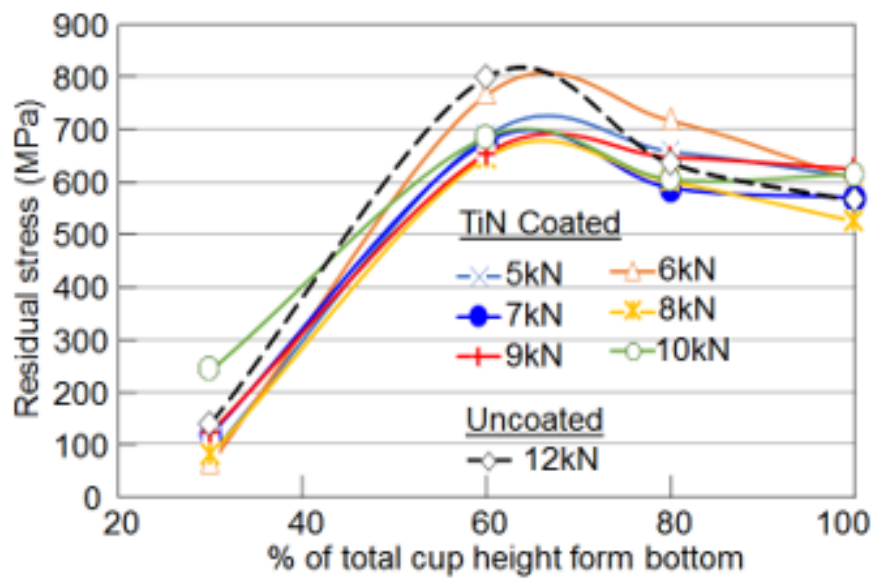

\section{Figure 15}

Longitudinal distributions of residual hoop stresses passing through valley points along the outer surfaces of the crack-free cups 